\title{
TANI İLIŞKILİ GRUPLARA (DRG) GÖRE HASTANELER VE ÜLKELER ARASI KARŞILAŞTIRMA: BİR VAKA ÖRNEĞİ
}

\author{
TO DIAGNOSIS RELATED GROUPS (DRG) BY COMPARISON BETWEEN HOSPITAL \\ AND COUNTRY: A CASE STUDY
}

\author{
Yıldız AYANOĞLU ${ }^{1}$ \\ Umut BEYLİK ${ }^{2}$ \\ Fatih ORHAN ${ }^{3}$
}

\section{$\ddot{O ̈ z}$}

Bu çalışmada; seçilmiş 4 hastanede bir yıllık DRG verileri içinde Solunum Sistemi Enfeksiyon (E62) vakalarına giren hastalar demografik, klinik ve finansal açıdan karşılaştırmalı değerlendirilmesi amaçlanmıştır. Çalışma verileri, 2011 yılında Sağlık Bakanlığına bağlı Göğüs Hastalıkları Hastanelerinde yatarak tedavi gören E62 vakalarını içermektedir. Bu vakalar demografik verileri, ortalama kalış süreleri, taburculuk durumları, vaka karma indeksleri, bağıl değerler ve geri ödeme miktarları açısından hastane ve ülke bazında karşılaştııılmıştır. E62 vakaları erkeklerde \% 67, kadınlarda \% 33 oranında görülmüştür. E62C DRG'sinin \%52 görülme oranıyla en sık görülen E62 vakası olduğu, E62 vakaları için ortalama hastanede kalış süresinin 18,7 gün olduğu, E62 vakalarının \% 91,4 oranla şifa durumu ile taburcu edildiği, hastane geri ödemelerinde bağıl değerlerin ve E62 DRG çeşitliliği frekanslarının doğrudan etkili olduğu ve vaka karma indeksleri ile geri ödeme miktarı arasında pozitif yönlü ilişki olduğu tespit edilmiştir. Hem hastaneler arasında hem de ülkeler arasında DRG verileri bakımından önemli oranda farklılıklar olduğu tespit edilmiştir. DRG verilerinin finansman amaçlı kullanımı yanında vakaların epidemiyolojik ve demografik parametreler açısından karar destek sistemleri için önemli bir kaynaktır. Diğer DRG vakaları içinde analiz çalışmaları yapılması, vaka bazlı sağlık planlamalarına önemli oranda katkı sağlayacağı düşünülmektedir.

Anahtar Kelimeler: Tanı İlişkili Gruplar, Solunum Sistemi Enfeksiyonları, Bağıl Değer, Geri Ödeme, Vaka Karma İndeksi

\begin{abstract}
In this study; DRG data was gathered in one year in four different hospitals where Respiratory Infections (E62) cases of patients were evaluated in order to retain their demographic, clinical and financial backgrounds.. Study data, attached to the Ministry of Health in 2011 in Chest Diseases Hospital inpatient cases include E62. These cases demographic data, the average length of stay, discharge status, case mix index, in terms of relative values and repayment amounts were compared on the basis of hospitals and countries. E62 cases in men 67\%, women $33 \%$ were observed. E62C drg's 52\% of the incidence of the most common E62 cases where, E62 cases the average length of hospital stay of 18.7 days, which was the E62 cases of $91.4 \%$ compared healing with the condition were discharged, hospital reimbursement in the relative values and E62 DRG diversity frequencies that are directly affected and with case-mix index is a positive correlation between the amount of reimbursement have been identified. Both between countries and between hospitals terms DRG data were found to be significantly different. Besides the use of DRG data for the financing of the cases in terms of epidemiological and demographic parameters is an important resource for decision support systems. DRG analysis studies done in other cases, case-based health planning is expected to contribute significantly to.
\end{abstract}

Key Words: Diagnostic Related Groups, Respiratory İnfections, Relative Value, Payback, Case Mix Index.

\footnotetext{
${ }^{1}$ Doç.Dr., Gazi Üniversitesi İIBF Öğretim Üyesi, yildiz.ayanoglu@gazi.edu.tr

${ }^{2}$ Dr., Sağlık Bakanlığı, beylik28@gmail.com

${ }^{3}$ GATA SAMYO Öğretim Görevlisi, forhan@gata.edu.tr
} 


\section{GİRIŞ}

Halen Dünya'da birçok gelişmiş ülkede kullanılmakta olan “Tanı İlişkili Gruplar” yani DRG (Diagnostic Related Groups)'ler: hastanelerin tedavi ettiği hasta türlerini anlamak, hastaların ne kadar "hasta" olduklarını/hastalık şiddetlerini ölçmek, bir hastanenin tedavi ettiği hastalar açısından neden bir başka hastaneye göre daha fazla kaynak ihtiyacı olduğunu anlamak, hasta bakımının finansmanını sağlamak, hastaneler arasındaki farklılıkları ortaya koymak ve uluslararası karşılaştırmalar yapmak amacıyla benzer klinik ve maliyet özelliklerine sahip hastane vakalarını tespit etmeye ve gruplamaya yarayan bir araçtır.

DRG'lerin; klinik faaliyetlerin ölçülmesi, finansman arac1, hastane için yönetim arac1, kalite ve kullanım ölçümlerine başlamak için bir araç, hastanede klinik ve finansal kararların verilmesi vb. kullanım alanları bulunmaktadır. DRG'ler Sağlık Bakanlığı, Sosyal Güvenlik Kurumu gibi merkezi kurumlara; hangi sayıda, hangi tip hastaların kim tarafindan tedavi edildiğinin anlaşılması, izleme sistemlerinin oluşturulması, kaynak tahsisi, karşılaştırmalı veri analizlerinin hazırlanması ve çeşitli göstergeler kullanılarak performansın izlenmesi gibi olanaklar sunmaktadır. Hastanelere; hangi sayıda, hangi tip hastaların kim tarafindan tedavi edildiğinin anlaşılması, hastane, bölüm, hekim, vs. düzeyinde izlemelerin ve analizlerin yapılması, kullanılmakta olan bakım yöntemlerinin ve sonuçlarının geliştirilmesi, hastane içi maliyetlerin kontrol edilmesi, karşılaştırmalı veri analizlerinin hazırlanması ve çeşitli göstergeler kullanılarak performansın izlenmesi gibi yönetsel olanaklar sunmaktadır.

Solunum Sistemi Enfeksiyonları Türkiye'de ve pek çok ülkede en sık görülen vakalar arasındadır. DRG uygulaması ile vakaların demografik olarak görülme sıklığının belirlenmesi ile bakım ve tedavi hizmetlerinin hastaneler arasındaki farklılıklarının ortaya konması koruyucu ve tedavi edici sağlık hizmetleri açısından yönlendirici olmakla birlikte ayrıca sağlık hizmetlerinin finansmanı konusunda da sağlık kurumları için daha doğru ve hakkaniyetli bir kaynak dağıtımı noktasında önemli veriler sağlanabilmektedir. Bu çalışma ile Solunum Sistemi Enfeksiyonları DRG vakaları özelinde hastaneler ve ülkeler arasında karşılaştırmalar ve değerlendirmelerde bulunularak vaka yapıları hakkında yönlendirici sonuçlar ortaya konulmaya çalışılmıştır. Bu vakalar bazında ortaya konan bulgu ve değerlendirmeler; DRG finansman sistemi açısından doğrudan değerlendirilebileceği, dolaylı olarak da koruyucu ve tedavi edici hizmetlerin planlanmasında veri olarak kullanılabileceği düşünülmüş olup, bakım ve tedavi hizmetlerinin nasıl yapılacağı hakkında bir değerlendirme içermemektedir. 


\section{Solunum Sistemi Enfeksiyonları Vakalarına ve Tanı İlişki Gruplar (DRG) Yapısına Genel Bakış}

\subsection{Solunum Sistemi Enfeksiyonları Hakkında Genel Bilgiler}

Solunum sistemi; burun, ağız, bademcikler, boğaz, ses telleri, geniz, soluk borusu, akciğer içi hava yolları ve akciğer gibi organlardan oluşur. Ağız, burun, boğaz ve bademciklerin iltihaplanmasına üst solunum yolu enfeksiyonları denir. Soğuk algınlığı, üşütme diye bilinen nezle, farenjit ve tonsillit üst solunum yollarında bulunan ve hastalık yapan mikropların soluk borusu ve akciğerlerle, akciğer içi hava yollarını iltihaplandırmasına alt solunum yolu enfeksiyonları denir. Solunum yolu enfeksiyonları Türkiye'de çocuk hastalıkları ve ölümlerinin ana sebeplerindendir. Solunum yolu hastalıkları daha çok kış ve bahar aylarında soğuğun vücut direncini düşürmesi ile solunum yollarının mikroplar tarafindan iltihaplanmasıyla meydana gelir. 200'den fazla sayıdaki virüsler üst solunum yolu enfeksiyonlarına neden olabilir. Bu virüsler çok hızlı yayılır ve çok bulaşıcıdır. $\mathrm{Bu}$ virüsler herhangi bir kişinin solunum yoluna tokalaşma gibi direk temas yolu ile yiyecek veya içecek paylaşımı ve öpüşme gibi temas ile bulaşabilir. Ayrıca, öksürük ve hapşırma yoluyla da yayılabilir. En sık görülen neden, enfekte yüzeylere dokunduktan sonra kendi elleri ile gözlerini, burun veya ağıza dokunarak bulaştırmasını içerir. Akut farenjit hastalığına bazı bakteriler de neden olabilir (http://www.saglikvakti.com).

\subsection{DRG Kavramı ve Vaka Karması}

Tanı İlişkili Gruplar; hastaların klinik ve maliyet verilerinin kullanılarak gruplandırılmasını ve benzer hastalıkların benzer gruplara atanmasını içeren yatan hasta sınıflandırma sistemidir. Sınırlı kaynakları vakaların türlerine ve şiddetine dayalı olarak adil biçimde dağıtır.

Tanı ilişkili gruplar 1970'li yıllarda, Amerika Birleşik Devletlerinde Yale Üniversitesi’nde sağlık hizmetlerinin kalite denetimi amacıyla geliştirilmiş bir araç olup 1980 yılından itibaren geri ödemelerde de kullanılmaya başlanan bir vaka sınıflama sistemidir. 1983 yılında Medicare kapsamına alınmıştır. Sonrasında maliyet verileri kullanılarak ödeme modeline dönüştürülmüştür (www.tig.saglik.gov.tr).

Hastane verimliliğini ve etkililiğini teşvik eder. DRG; sistematik, anlamlı klinik veri toplar. DRG'de amaç (TİG Uygulama Rehberi, 2011):

- Hastalık grupları arasında maliyet farklılıklarını ortaya koymak 
- Yönetilebilir bir ödeme yöntemine geçmek

- Sağl1k insan gücü planlaması yapmak

- Planlama ve araştırmalara 1şık tutmak

- TİG uygulayan ülkelerle karşılaştırma yapmak

- Hastane yönetim aracı olarak kullanmak

Băgll Değer; Bir DRG' in maliyetinin, tüm DRG'lerin ortalama maliyetine oranıdır (TİG eBülten, 2009).

Bağıl Değer $=\frac{\text { Bir DRG için Ortalama Maliyet }}{\text { Tüm Grubun Tüm Vakalarını (DRG’leri) Temsil Eden Genel Ortalama Maliyet }}$

Bağıl Değer formülünde hem payı hem de paydayı hesaplamak için maliyet verileri gereklidir.

Vaka Karma İndeksi (VKİ) (TİG e-Bülten, 2009):

- Bir hastanenin vaka üretimini bir başka hastane ile karşılaştırmayı sağlayan orandir.

- Kompleksliğin ölçülmesidir.

- Hastaların ne kadar "hasta" olduğunu ölçmenin bir göstergesidir.

Hastane Vaka Karma İndeksi $=\frac{\sum(\text { DRG Bağıl Değer X Vaka Sayısı) }}{\text { A Hastanesi için toplam vaka sayısı }}$

Vaka karması terimi, bir hastane ya da birim tarafından tedavi edilen hastaların türü veya karmasını ifade eder. Hastaların türü veya karmasını belirleyebilmek için sınıflama sistemlerine ihtiyaç vardır. En bilinen sınıflama sistemlerinden birisi DRG. Bunun dışında benzer nitelikte HRG (Healthcare Resource Group), LDF (Austrian Leistungsorien Diagnosen Fallgruppen), DBC (Diagnosis Treatment Combination) gibi hastalık sinıflama sistemleri de mevcuttur. DRG, bir hasta yatışının gruplandırılmasıdır. Bu gruplama için Tablo 1'deki verilere ihtiyaç bulunmaktadır (Şencan ve Demir, 2013). 
Tablo 1. DRG için gerekli Demografik ve Klinik Veriler

\begin{tabular}{|l|l|}
\hline \multicolumn{2}{|c|}{ Demografik Veriler } \\
\hline Yaş & Yeni doğanlar dışında yıl olarak alınması yeterlidir. \\
\hline Cinsiyet & Erkek veya kadın \\
\hline Taburcu Şekli & $\begin{array}{l}\text { Hastanın taburcu edildiği sıradaki durumu (Şifa, Ölüm) ve ilgili } \\
\text { olduğu hallerde gideceği yeri (Sevk, İstekle Ayrılış vb.) ifade eder. }\end{array}$ \\
\hline $\begin{array}{l}\text { Yenidoğanın } \\
\text { doğum ağırlığı }\end{array}$ & Doğum ağırlığı DRG gruplaması için kullanılan verilerden biridir. \\
\hline & \multicolumn{1}{c|}{ Klinik Veriler } \\
\hline Ana Tanı & $\begin{array}{l}\text { Araştırma sonunda, hastanın hastanedeki yatışının esas nedeni } \\
\text { olarak ortaya konulan tanıdır veya ana yatış nedenidir. }\end{array}$ \\
\hline İşlem(ler) & $\begin{array}{l}\text { Genellikle, DRG ataması üzerinde yalnızca bir işlem etkilidir. } \\
\text { Birden fazla işlemin kaydedildiği durumda, kaynak kullanımının } \\
\text { yüksek olduğu DRG'lere doğru bir geçiş olur. }\end{array}$ \\
\hline Ek Tanı(lar) & $\begin{array}{l}\text { Gerek ana tanı ile birlikte seyreden (komorbidite) gerek hasta } \\
\text { yatışında ortaya çıan (komplikasyon) bir durum veya şikayet. }\end{array}$ \\
\hline
\end{tabular}

\subsection{DRG Uygulamasına Genel Bakış}

Dünyada TİG'lerin çeşitli kullanım alanları mevcuttur. Bunlar aşağıdaki gibi sıralanabilir (Şencan ve Demir, 2013):

- Klinik faaliyetlerin ölçülmesi,

- Hastanede klinik ve finansal kararların verilmesi,

- Hastane içi ve hastaneler arası bakım kalitesi karşılaştırmaları,

- Klinik rehberler, protokoller ve sürekli kalite gelişimi projeleri için destek sağlaması,

- Veri ve tanımlama standartlarının oluşturulması,

- DRG'ye dayalı bütçeleme modellerinde maliyetlerin etkili bir şekilde takip edilmesi.

Türkiye'de DRG Çalışmaları (www.tig.saglik.gov.tr):

Vaka karması sistemi çalışmaları önderliğini Türkiye'de Sağlık Bakanlığı yapmaktadır. Bu çalışmalara 2005 yılında Avustralya modeli baz alınarak başlanmıştır. Üniversite, özel sektör ve resmi temsilcilerle ortak çalışmalar sürdürülmüştür. 2009 yılında bu konu ile ilgili gerekli çalışmaları yapacak birim Sağlık Bakanlığı Tedavi Hizmetleri Genel Müdürlüğüne bağlı bir 'şube olarak' kurulmuştur. Bakanlık organizasyon yapısındaki değişiklikler nedeni ile 2012 yılında Sağlık Hizmetleri Genel Müdürlüğü altında 'Daire Başkanlığı’ haline getirilmiştir. Toplanan veriler ilk olarak Bakanlık Global bütçesi devlet hastanelerine dağıtılırken kullanılmıştır. 
DRG Klinik Veri Giriş Programı (TİG Uygulama Rehberi, 2011):

DRG Klinik Veri Giriş programı hasta düzeyinde gerekli medikal ve finansal verilerin mümkün olduğunca hızlı, doğru ve güvenli bir şekilde toplanması, hasta bazında DRG (Diagnosis Related Group)'lerin otomatik oluşturulması ve de sonrasında gerekli analizlerin yapılabilmesi amacıyla geliştirilmiştir. DRG Klinik Veri Girişi internet üzerinden çalışan bir sistemdir.

Klinik kodlama biriminde üretilen ve hastanın klinik seyrini gösteren ICD 10 AM (Hastalıkların Uluslar arası Sinıflandırılması 10. Versiyon Avustralya Uyarlaması) kodları veri tabanına DRG Klinik Veri Giriş programı aracılığı ile gönderilmektedir. Hastane Bilgi Sisteminde yer alan hastaya ait demografi ve maliyet verileri alınarak XML dosyası aracılığ ile DRG Klinik Veri Giriş programına entegre edilmektedir. Programa kaydı yapılan her hasta için gruplama programı aracılığı ile nihai DRG oluşturulmaktadır.

Şekil 1. Tanı İlişkili Gruplar (DRG / TİG) Oluşum Süreci

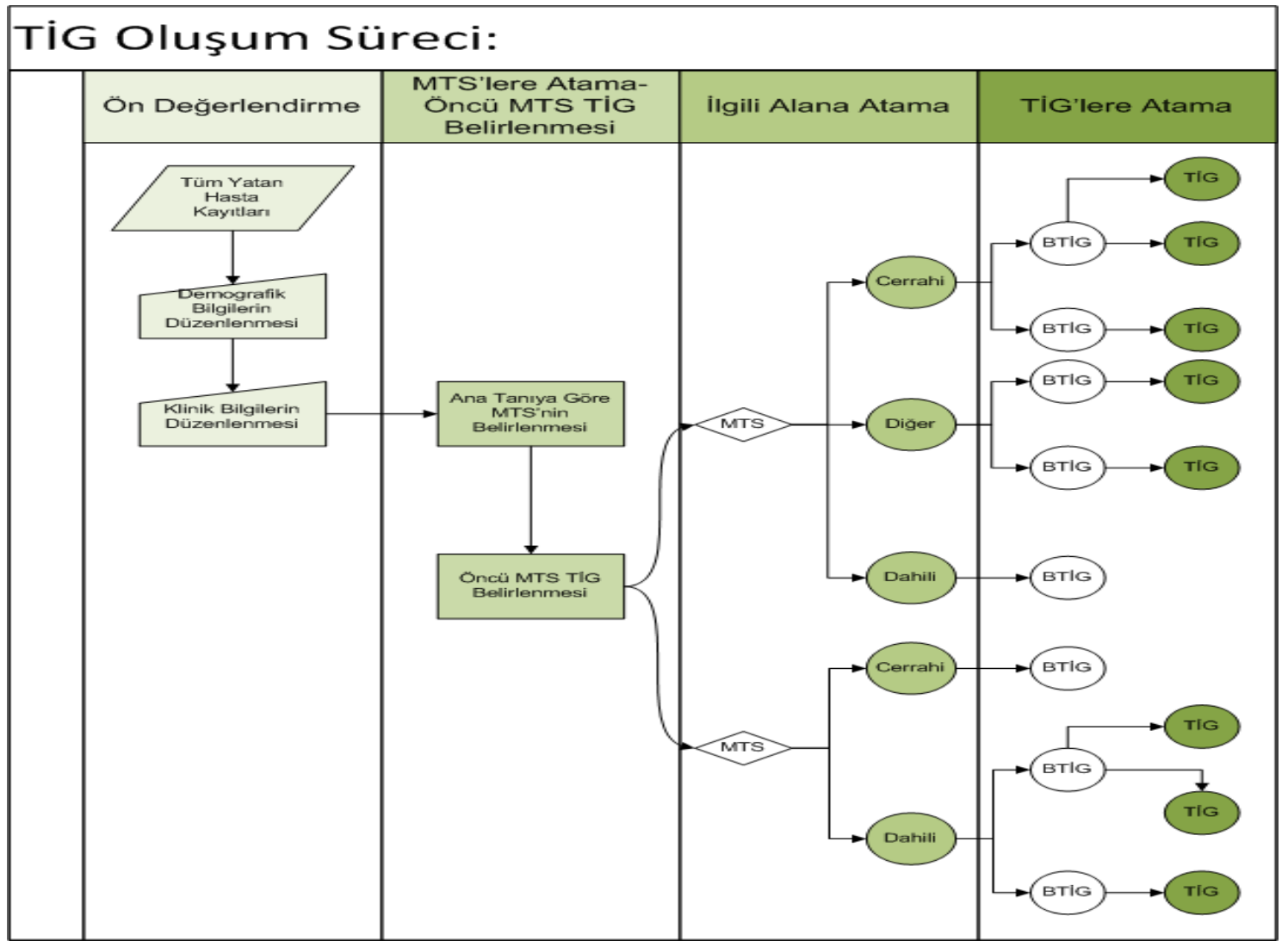




\section{Klinik Maliyetlendirme}

Mali veriler, ülkelerin muhasebe standartlarına göre şekillenen bir yapıda incelenmektedir. Türkiye'de Tek Düzen Muhasebe Sistemi (TDMS)'ne geçilmesinden bu yana standartlar oluşturulmuştur. Yönetim muhasebesi için ise temel kurallar belli olmakla birlikte genelde insiyatif yönetim muhasebesi uygulayan kurumlara bırakılmıştır. Sağlık işletmeleri diğer işletme tiplerinden farklılıkları göz önünde bulunularak irdelenmeli ve uygulamalar buna göre geliştirilmelidir (Hacettepe Üniversitesi, 2006).

Klinik maliyetlendirme (clinical costing), maliyet muhasebesi yöntemleri ile ünite bazında oluşturulan maliyetlerin klinik veriler ile birleştirilmesidir. Klinik veriler açısından ülkeler farklı sinıflandırma sistemlerini kullanabilirler ve buna göre bir yönetim sistemi içerisinde karar destek aracı oluşturmaktadırlar. Gelişmiş sağlık sistemlerinde ülkeler kendi tanı ve prosedür kod sınıflamalarını kullanmaktadır. Örneğin Avustralya'da ICD 10 AM (Hastalıkların Uluslararası Sinıflandırılması 10. Versiyon Avustralya Uyarlaması) ve ACHI (Avustralya Sağlık İşlemleri Sınıflandırması) gibi. Bu kodlama standartlarına göre de farklı gruplamalar oluşturulmaktadır. AR-DRG (DRG Avustralya Uyarlaması) gibi. Türkiye'de hastalık gruplamaları için bir çalışma olmadığı için ICD 10 AM ve ACHI üzerinden oluşturulan AR-DRG kullanılmaktadır. Mali veriler açısından ise ülkeler genel kabul görmüş maliyet muhasebesi standartları kullanmaktadırlar. Türkiye'de bu tür çalışmaları 2005 yılında başlatılmıştır.

\section{Tanı İlişkili Gruplar Verileri Kapsamında Solunum Sistemi Enfeksiyon Vakaları: Hastaneler ve Ülkeler Arası Karşılaştırma ve Değerlendirmeler}

\subsection{Literatür}

Türkiye'de bilimsel olarak 2014 yılına kadar DRG uygulaması ile ilgili 2 adet yüksek lisans tezi yapılmış olup, bunlar da DRG'nin uygulanmasına yönelik Türkiye'deki Hekim ve Sağlık Yöneticilerinin tutum ve davranışları ile ilgili (anket) çalışmalardır. Solunum Sistemi Enfeksiyonları ile ilgili pek çok akademik yayın bulunmakla birlikte bu vakalara DRG bazlı yaklaşımları içeren bilimsel çalışmalar bulunmamaktadır. Ancak Avustralya ve Almanya başta olmak üzere bazı ülkeler DRG verilerini dönemsel olarak yayınlamaktadırlar.

Dünya'da yaklaşık 30 yıllık geçmişi olan DRG üzerine yapılan çalışmalar genellikle maliyet hesaplamalarından Bağıl Değerlerin tespitine, DRG algoritmalarının oluşturulup güncellenmesine ve DRG kodlamalarına yönelik olmuştur. Türkiye'de ise 2005-2009 yılları arasında gerçekleştirilen DRG Projesi ile klinik ve mali veriler toplanmış, bu süreçte işlem 
basamakları başta olmak üzere nasıl bir yöntem izlendiğini içeren rapor niteliğinde dokümanlar yayınlanmıştır. Sağlık Bakanlığı ise 2009 yılından itibaren DRG klinik kodlaması üzerine sağlık kurumlarına rehberlik edecek dokümanlar yayınlamış, ve yine pilot uygulamalar yaparak 2011 yılı için Türkiye Bağıl Değer setini oluşturmuştur. Görüldüğü üzere Türkiye'de DRG uygulaması henüz geliştirilme düzeyinde olup, halen DRG uygulamasına geçiş süreci devam etmektedir.

\subsection{Amaç, Veriler, Varsayımlar, Kapsam ve Sınırlılıklar}

$\mathrm{Bu}$ çalışma ile seçilmiş hastanelerde DRG Solunum Sistemi Enfeksiyonları vakaları karşılaştırılarak hastaneler ve ülkeler arasında benzerlik ve farklılıklar ortaya konarak değerlendirmeler yapılmış ve ortaya çıkan sonuçlara göre önerilerde bulunulmuştur. Sağlık Bakanlığından elde edilen veriler 2011 yılını kapsamaktadır. Temin edilen verilerin doğru olduğu varsayılmıştır. Veriler solunum sistemi enfeksiyon vakalarına ait olup, 3’ü Eğitim ve Araştırma Hastanesi ve 1'i Özel Dal Hastanesi olmak üzere 4 adet Göğüs Hastalıkları ve Cerrahisi alanında hizmet veren Sağlık Bakanlığı Hastanelerini kapsamaktadır. Çalışmanın daha yönetilebilir olması açısından hastane sayısı sınırlı tutulmuş ve bu vaka türü açısından yoğun hizmet veren hastanelere ait veriler temin edilmiştir.

İlgili hastaneler ve temel istatistiki verileri Tablo 2'de gösterilmiştir.

Tablo 2. Örneklem Hastane Temel İstatistikleri, 2011

\begin{tabular}{|c|l|c|c|c|}
\hline $\begin{array}{c}\text { Hastane } \\
\text { Adı }\end{array}$ & \multicolumn{1}{|c|}{ Hastaneler } & $\begin{array}{c}\text { Yatak } \\
\text { Yatak } \\
\text { Sayısi }\end{array}$ & $\begin{array}{c}\text { Doluluk } \\
\text { Oranı } \\
\mathbf{( \% )}\end{array}$ & $\begin{array}{c}\text { Ortalama } \\
\text { Kalış } \\
\text { Günü }\end{array}$ \\
\hline A Hastanesi & $\begin{array}{l}\text { İstanbul Süreyyapaşa Göğüs Hastalıkları ve Cerrahisi Eğitim } \\
\text { ve Araştırma Hastanesi }\end{array}$ & 904 & 74,8 & 5,1 \\
\hline B Hastanesi & $\begin{array}{l}\text { İzmir Dr.S.Seren Göğüs Hastalıkları ve Cerrahisi Eğitim ve } \\
\text { Araştırma Hastanesi }\end{array}$ & 279 & 52,6 & 3,5 \\
\hline C Hastanesi & $\begin{array}{l}\text { Ankara Atatürk Göğüs Hastalıkları ve Cerrahisi Eğitim ve } \\
\text { Araştırma Hastanesi Hastanesi }\end{array}$ & 304 & 73,4 & 3,1 \\
\hline D Hastanesi & Denizli Buldan Göğüs Hastalıkları Hastanesi & 688 & 72,3 & 4,9 \\
\hline
\end{tabular}

AR DRG algoritması içerisinde bulunan 665 DRG içerisinde solunum sistemi enfeksiyon vakaları 3 ciddiyet düzeyi ile tanımlanmıştır:

E62A: Solunum Sistemi, Enfeksiyon/Enflamasyon, Katastrofik KK (Komplikasyon/Komorbidite) Bulunan, 
E62B: Solunum Sistemi, Enfeksiyon/Enflamasyon, Şiddetli/Orta Şiddetli KK Bulunan, E62C: Solunum Sistemi, Enfeksiyon/Enflamasyon, KK Bulunmayan olmak üzere 3 adet bu vaka ile ilgili DRG çeşidi mevcuttur.

Bu üç DRG çeşidi MTS (Majör Tanı Sınıfi) - 04 Solunum Sistemi Hastalıkları grubunda yer almaktadır ve bu DRG çeşitleri Tablo 3'de belirtilen tanılar ile oluşmaktadır.

Tablo 3. E62A-E62B-E62C DRG Vakaları Ana Tanı ICD 10 Kodlar1

\begin{tabular}{|c|c|c|c|c|}
\hline ICD $10 \mathrm{Kod}$ & ICD 10 Kod Açıklama & E62A & E62B & E62C \\
\hline A.15 & Solunum yolları tüberkülozu, bakteriyolojik ve histolojik olarak doğrulanmış & $*$ & $*$ & $*$ \\
\hline A.16 & Solunum yolu tüberkülozu, bakteriyolojik ve histolojik olarak doğrulanmamış & * & * & $*$ \\
\hline A.20.2 & Pnömonik Veba & * & 0 & o \\
\hline A31.0 & Pulmoner mikobakteriyel enfeksiyon & * & o & $*$ \\
\hline B67.1 & Akciğerin Echinococcus granulosus enfeksiyonu & * & $*$ & $*$ \\
\hline $\mathrm{J} 10$ & Tanımlanmış influenza virüsüne bağlı influenza & o & o & $*$ \\
\hline $\mathrm{J} 11$ & İnfluenza, tanımlanmamış virüs & $*$ & $*$ & $*$ \\
\hline $\mathrm{J} 12$ & Viral pnömoni, başka yerde sınıflandırılmamış & o & $*$ & 0 \\
\hline $\mathrm{J} 13$ & Streptococcus pneumoniae'ya bağlı pnömoni & o & $*$ & o \\
\hline $\mathrm{J} 14$ & Haemophilus influenza'ya bağlı pnömoni & $*$ & $*$ & $*$ \\
\hline $\mathrm{J} 15$ & Bakteriyel pnömoni, başka yerde sınıflandırılmamış & $*$ & $*$ & $*$ \\
\hline $\mathrm{J} 16$ & Diğer enfeksiyöz organizmalara bağlı pnömoni, başka yerde sınıflandırılmamış & * & $*$ & $*$ \\
\hline $\mathrm{J} 18$ & Pnömoni, organizma tanımlanmamış & $*$ & $*$ & $*$ \\
\hline J69 & Katı ve sıvılara bağlı pnömoni & * & $*$ & o \\
\hline J85 & Akciğer ve mediyasten apsesi & * & * & $*$ \\
\hline $\mathrm{J} 86$ & Piyotoraks & $*$ & $*$ & $*$ \\
\hline J92 & Plevral plak & $*$ & $*$ & 0 \\
\hline J94 & Diğer plevral durumlar & $*$ & 0 & * \\
\hline R09 & Dolaşım ve solunum sistemine ait diğer semptom ve belirtiler & $*$ & $*$ & $*$ \\
\hline
\end{tabular}

Temin edilen veriler ham halde olup, 2011 yılında 4 hastanede görülen toplam 6275 adet solunum sistemi enfeksiyonu vakalarına ait demografik (yaş ve cinsiyet) ve klinik (atandıkları DRG'leri) verileri içermektedir. Ayrıca DRG algoritması olarak Avustralya Uyarlaması (AR-DRG) kullanılmıştır. Yine finansman amaçlı karşılaştırma yapmak için ilgili DRG’lerin Türkiye Bağıl Değerleri Sağlık Bakanlığı'ndan, Avustralya Bağıl Değerleri Avustralya Sağlık Bakanlığı web sitesinden (www.health.gov.au) ve Almanya Bağıl Değerleri de Almanya DRG Enstitüsü web sitesinden (www.g-drg.de) temin edilmiştir. 


\subsection{Solunum Sistemi Enfeksiyon Vakalarının Demografik Veriler Açısından Karşılaştırması}

Temin edilen veriler hastane bazında cinsiyete göre ayrıştırılarak Tablo 4'de gösterilmiştir.

Tablo 4. DRG Solunum Sistemi Enfeksiyon Vakaları Cinsiyet Dağılımı

\begin{tabular}{|l|c|c|c|c|c|}
\hline \multirow{2}{*}{ Hastaneler } & \multicolumn{2}{|c|}{ Erkek } & \multicolumn{2}{c|}{ Kadın } & \multirow{2}{*}{ Toplam } \\
\cline { 2 - 6 } & Sayı & Oran (\%) & Sayı & Oran (\%) & \\
\hline A Hastanesi & 1621 & 63 & 947 & 37 & 2568 \\
\hline B Hastanesi & 1328 & 70 & 581 & 30 & 1909 \\
\hline C Hastanesi & 1135 & 71 & 473 & 29 & 1608 \\
\hline D Hastanesi & 120 & 63 & 70 & 37 & 190 \\
\hline Toplam & $\mathbf{4 2 0 4}$ & $\mathbf{6 7}$ & $\mathbf{2 0 7 1}$ & $\mathbf{3 3}$ & $\mathbf{6 2 7 5}$ \\
\hline
\end{tabular}

Tablo 4 değerlendirildiğinde sadece tüm hastanelerde erkek vakalarının kadın vakalardan fazla olduğu görülmüştür. Hastanelerde \% 67 erkek, \% 33 kadın vaka görülme oranları, bu vakaların erkeklerde daha sık görüldüğünü, C Hastanesinde erkeklerde \%71'lik oran ile en yüksek görülme oranına sahip hastane olduğu ortaya çıkmıştır. Özellikle soğuk mevsimlerde sık karşılaşılan bu vakaların, kadınlara göre erkeklerde daha sık görülme nedeni olarak iklim şartlarına erkeklerin daha fazla maruz kalması nedeni ile olabileceğini düşündürmüştür. C Hastanesinin bulunduğu coğrafi konum itibarı ile daha soğuk iklim şartlarına sahip olması dolayısıyla burada daha fazla erkek vakanın görülmesi normal karşılanmıştır.

Temin edilen veriler hastane bazında yaş dağılımına göre ayrıştırılarak Tablo 5'de gösterilmiştir. 
Tablo 5. DRG Solunum Sistemi Enfeksiyon Vakaları Yaş Dağılımı

\begin{tabular}{|l|c|c|c|c|}
\hline \multicolumn{1}{|c|}{ Hastaneler } & E62A & E62B & E62C & $\begin{array}{c}\text { Tüm } \\
\text { Vakalar }\end{array}$ \\
\hline A Hastanesi & 66 & 56 & 38 & $\mathbf{5 0}$ \\
\hline B Hastanesi & 70 & 64 & 52 & $\mathbf{5 9}$ \\
\hline C Hastanesi & 68 & 59 & 49 & $\mathbf{5 1}$ \\
\hline D Hastanesi & $0^{*}$ & 67 & 53 & $\mathbf{5 7}$ \\
\hline Ortalama & $\mathbf{6 7}$ & $\mathbf{6 0}$ & $\mathbf{4 6}$ & $\mathbf{5 3}$ \\
\hline
\end{tabular}

*: Vaka bulunmamaktadır

Tablo 5'e göre tüm hastanelerde ortalama yaş 53 olarak tespit edilmiştir. Genel olarak yaş dağılımları incelendiğinde vakaların ciddiyet düzeyi ile uyumlu olduğu görülmüştür. En ciddi vaka olan E62A tüm hastanelerde ortak olarak (ortalama 67 yaş) en yüksek yaş ortalamasına sahip iken en hafif vaka olan E62C en düşük yaş ortalamasına (46 yaş) sahip çıkmışlardır. Bu kapsamda yapılan değerlendirmede; E62A vakası için daha yüksek yaşta olanların ek hastalıklarının olabileceği ve bakım ile tedavi hizmetlerinin de daha komplike olabileceği öngörülmüştür.

Hastane bazında değerlendirme yapıldığında A Hastanesinin tüm vakalarda en düşük yaş ortalamasına sahip hastane olduğu görülmüştür. Diğer hastanelerde ise yaş ortalamaları vaka türlerine göre farklılık gösterdiği tespit edilmiştir. A Hastanesi diğer hastanelere göre daha hem kapasite hem de hizmet çeşitliliği bakımından büyük bir hastane olmakla birlikte ayrıca veri tabanı incelendiğinde önemli sayıda genç ve çocuk hasta vakalarına diğer hastanelere göre daha fazla rastlandığı belirlenmiştir.

\subsection{DRG Solunum Sistemi Enfeksiyon Vakalarının Vaka Sayıları ve Ortalama Kalış Süreleri Açısından Karşılaştırması}

Solunum Sistemi Enfeksiyon vakaları DRG çeşitliliği ve hastane bazında vaka sayıları Tablo 6'da gösterilmiştir. 
Tablo 6. DRG Solunum Sistemi Enfeksiyon Vaka Sayıları

\begin{tabular}{|l|c|c|c|c|c|c|c|}
\hline \multirow{2}{*}{ Hastaneler } & \multicolumn{2}{|c|}{ E62A } & \multicolumn{2}{c|}{ E62B } & \multicolumn{2}{c|}{ E62C } & \multirow{2}{*}{ Toplam Vakalar } \\
\cline { 2 - 8 } & Sayı & Oran (\%) & Sayı & Oran (\%) & Sayı & Oran (\%) & \\
\hline A Hastanesi & 346 & 13 & 1129 & 44 & 1093 & 43 & $\mathbf{2 5 6 8}$ \\
\hline B Hastanesi & 192 & 10 & 862 & 45 & 855 & 45 & $\mathbf{1 9 0 9}$ \\
\hline C Hastanesi & 26 & 2 & 372 & 23 & 1210 & 75 & $\mathbf{1 6 0 8}$ \\
\hline D Hastanesi & 0 & 0 & 59 & 31 & 131 & 69 & $\mathbf{1 9 0}$ \\
\hline Toplam & $\mathbf{5 6 4}$ & $\mathbf{9}$ & $\mathbf{2 4 2 2}$ & $\mathbf{3 9}$ & $\mathbf{3 2 8 9}$ & $\mathbf{5 2}$ & $\mathbf{6 2 7 5}$ \\
\hline
\end{tabular}

Tablo 6 incelendiğinde DRG'ler arasında yer alan E62C vakasının genelde en yüksek oranda görülen vaka (\%52), E62A vakasının ise tüm hastanelerde ve genelde en az görülen vaka olduğu tespit edilmiştir. A ve B Hastanelerinde E62B ve E62C vaka görülme sıklıkları neredeyse birbirinin aynı çıkmıştır. Özellikle mevsimsel hastalık özelliğinden dolayı bu vakalar soğuk mevsimlerde ortaya çıkmakta ve genellikle bilinen bakım ve tedavi yöntemleri ile etkili bir şekilde ağırlaşmadan iyileştirilebildiği söylenebilir. Bu kapsamda taburculuk durumları ile birlikte değerlendirme yapmak daha gerçekçi bir sonuç ortaya koyabilecektir. Daha ileri yaşlarda görülen E62A vakası açısından bakıldığında ise nispeten işgücü içerisinde yer almayan kesim oldukları için, vaka sayısı olarak daha az görülmeleri ile ilişkilendirilmiştir.

Bu tabloda dikkat çeken bir diğer husus D Hastanesinde E62A vakasının görülmemiş olmasıdır. Diğer 3 hastane Eğitim ve Araştırma Hastanesi statüsünde ve kapsamlı büyük hastaneler, D Hastanesi ise çok daha küçük bir Özel Dal Devlet Hastanesidir. E62A vakasının Eğitim ve Araştırma Hastanelerinde daha sık görülmesi, bu tür hastanelerin kaynakları itibarı ile yeterli donanıma sahip olması ve diğer hastane türü ve bölgelerden daha ağır hasta kabul etmesi ile ilişkilidir. Yine burada da taburculuk durumları ile ilişkilendirme yaparak daha net değerlendirme yapılabileceği öngörülmüştür. Bu durumda daha kompleks yani komplikasyon ve ek hastalık içeren vakaların Eğitim ve Araştırma Hastanelerinde bulunduğu görülmüştür. $\mathrm{Bu}$ kapsamda ortaya çıkan bulgular, hastanelerin fonksiyon ve rollerine uygun bir görüntü oluşturmuştur.

DRG Solunum Sistemi Enfeksiyon vakaları DRG Çeşitliliği ve hastane bazında ortalama kalış süreleri Tablo 7'de gösterilmiştir. 
Tablo 7. DRG Solunum Sistemi Enfeksiyon Vakaları Ortalama Kalış Süreleri (Gün)

\begin{tabular}{|l|c|c|c|c|}
\hline \multicolumn{1}{|c|}{ Hastaneler } & E62A & E62B & E62C & $\begin{array}{c}\text { Tüm } \\
\text { Vakalar }\end{array}$ \\
\hline A Hastanesi & 17,2 & 18,2 & 24,9 & $\mathbf{2 0 , 9}$ \\
\hline B Hastanesi & 12,6 & 11,9 & 15,3 & $\mathbf{1 3 , 5}$ \\
\hline C Hastanesi & 17,8 & 24,1 & 21,7 & $\mathbf{2 2 , 2}$ \\
\hline D Hastanesi & o & 13,9 & 12,2 & $\mathbf{1 2 , 7}$ \\
\hline Ortalama & $\mathbf{1 5 , 6}$ & $\mathbf{1 6 , 7}$ & $\mathbf{2 0 , 7}$ & $\mathbf{1 8 , 7}$ \\
\hline
\end{tabular}

Tablo 7 değerlendirildiğinde ortalama yatış günü genel olarak vaka ciddiyet düzeyleri ile ters orantılı olarak ortaya çıkmıştır. Yani E62C vakası en yüksek ortalama kalış süresine sahip iken E62A vakası en düşük ortalama kalış süresine sahip çıkmıştır. Genel ortalama 18,7 gündür. Ancak hem hastane bazında hem de vaka bazında farklılıklar olduğu görülmüştür. Her hasta kendine özgü olmakla birlikte aynı zamanda bakım ve tedavi hizmetlerine verdikleri cevap da farklı olabilmektedir. Bir vakanın ağır ya da hafif olması, bakım ve tedavi işlemlerinin türleri ve miktarı bu vaka için ortalama kalış süresi ile ilişkilendirilememiştir. Ayrıca genel olarak ortalama kalış süresi uzun olan vakaların daha kısa olan vakalara göre daha yüksek Bağıl Değere sahip olması beklenmektedir. Ancak E62 vakası için bu durumun gerçekleşmediği görülmüş̧ür.

Bununla birlikte D Hastanesi vaka ciddiyet düzeyi ile uyumlu ortalama kalış süresine sahip tek hastane çıkmıştır. Yani daha ağır vaka olan E62B vakası, daha hafif olan E62C vakalarına göre daha yüksek ortalama kalış süresine sahip çıkmıştır.

Ortalama kalış süreleri açısından tüm vakalarda genel ve ayrı ayrı olarak Eğitim ve Araştırma Hastaneleri (A,B,C) ile D Hastanesi arasında farklılık olduğu görülmüştür. Daha az komplike vakaların yer aldığı D Hastanesinde ortalama kalış süresi 12,7 gün ile en kısa çıkmıştır.

\subsection{DRG Solunum Sistemi Enfeksiyon Vakalarının Taburculuk Durumları} Açısından Karşılaştırması

DRG Solunum Sistemi Enfeksiyon vakaları hastane bazında taburculuk durumlarına göre (oransal olarak, \%) Tablo 8'de gösterilmiştir. 
Tablo 8. DRG Solunum Sistemi Enfeksiyon Vakaları Taburculuk Durumları (Oran, \%)

\begin{tabular}{|l|c|c|c|c|c|}
\hline \multicolumn{1}{|c|}{ Hastaneler } & Sevk & Ölüm & Şifa & $\begin{array}{c}\text { Kendi } \\
\text { İsteği }\end{array}$ & Toplam \\
\hline A Hastanesi & 0,7 & 2,7 & 94,5 & 2,1 & 100,0 \\
\hline B Hastanesi & 1,3 & 7,6 & 88,3 & 2,8 & 100,0 \\
\hline C Hastanesi & 2,7 & 3,2 & 90,7 & 3,3 & 100,0 \\
\hline D Hastanesi & 5,8 & 2,6 & 85,3 & 6,3 & 100,0 \\
\hline Toplam & 1,5 & 4,3 & 91,4 & 2,7 & 100,0 \\
\hline
\end{tabular}

Tablo 8 değerlendirildiğinde tüm hastaneler bazında vakaların \% 91,4 oranında şifa sonucuyla taburcu edildikleri görülmüştür. Şifa ile taburcu edilen vakaların büyük çoğunluğu E62C vakası olup, bu vakadan görülen toplam ölüm sayısı sadece \%2 (bunların \%75'i E62B vakası) olduğu tespit edilmiştir. Tüm ölüm vakaları arasında E62A vakasından ölüm oranı \%39 iken, E62B vakası \%59 çıkmıştır. B ve C Hastaneleri’nde E62B vakasından ölümler diğer vakalara göre sık görülürken, A Hastanesinde E62A vakasından daha sık ölümler gerçekleşmiştir. Ayrıca D Hastanesinde en az ölüm vakasının görülmesi, en yüksek sevk ve kendi isteği ile ayrılma oranına sahip hastane çıkmış olması nedeniyle hastane türü ve kapasitesiyle uyumlu bir görüntü sergilemiştir. Eğitim ve Araştırma Hastanelerinde (A, B, C) taburcu durumu açısından bakıldığında ölüm ile sonuçlanan taburcu şeklinin özellikle B Hastanesinde (sonra sırasıyla C ve A Hastanesi) yüksek oranda görüldüğü tespit edilmiştir. Ayrıca buna ilaveten bu hastanelerde sevk oranları ile kendi isteği ile ayrılmaların düşük olması nedeniyle bu hastanelere gelen vakaların daha (D Hastanesine göre) ağır seyrettiğini nitelemiştir.

\subsection{DRG Solunum Sistemi Enfeksiyon Vakalarının Vaka Karma İndeksleri, Bağıl Değerler ve Geri Ödeme Açısından Karşılaştırması}

DRG Solunum Sistemi Enfeksiyon vakaları hastane ve ülke bazında vaka karma indeksleri (VKİ) Tablo 9'da gösterilmiştir. 
Tablo 9. DRG Vaka Karma İndeksleri (Türkiye - Avustralya - Almanya)

\begin{tabular}{|c|c|c|c|c|c|c|c|c|c|c|c|c|}
\hline \multicolumn{13}{|c|}{ DRG Solunum Sistemi Enfeksiyon Vaka Karma İndeksleri (Türkiye) } \\
\hline \multirow[b]{2}{*}{ Hastaneler } & \multicolumn{3}{|c|}{ E62A } & \multicolumn{3}{|c|}{ E62B } & \multicolumn{3}{|c|}{ E62C } & \multirow{2}{*}{$\begin{array}{c}\text { Toplam } \\
\text { Vaka Sayısı }\end{array}$} & \multirow{2}{*}{$\begin{array}{c}\text { Toplam } \\
\text { Ağırlıklandırılmış } \\
\text { Vaka }\end{array}$} & \multirow[b]{2}{*}{ VKI } \\
\hline & $\begin{array}{l}\text { Bağıl } \\
\text { Değer }\end{array}$ & $\begin{array}{l}\text { Vaka } \\
\text { Sayısı } \\
\end{array}$ & $\begin{array}{c}\text { Ağırlıkl. } \\
\text { Vaka } \\
\end{array}$ & $\begin{array}{l}\text { Bağıl } \\
\text { Değer }\end{array}$ & $\begin{array}{l}\text { Vaka } \\
\text { Sayısı } \\
\end{array}$ & $\begin{array}{c}\text { Ağırlıklandırılmış } \\
\text { Vaka }\end{array}$ & $\begin{array}{l}\text { Bağıl } \\
\text { Değer }\end{array}$ & $\begin{array}{l}\text { Vaka } \\
\text { Sayısı } \\
\end{array}$ & $\begin{array}{c}\text { Ağırlıklandırılmış } \\
\text { Vaka }\end{array}$ & & & \\
\hline A Hastanesi & 2,3 & 346 & 796 & 1,48 & 1129 & 1671 & 0,9 & 1093 & 984 & 2568 & 3450 & 1,34 \\
\hline B Hastanesi & 2,3 & 192 & 442 & 1,48 & 862 & 1276 & 0,9 & 855 & 770 & 1909 & 2487 & 1,30 \\
\hline C Hastanesi & 2,3 & 26 & 60 & 1,48 & 372 & 551 & 0,9 & 1210 & 1089 & 1608 & 1699 & 1,06 \\
\hline D Hastanesi & 2,3 & 0 & 0 & 1,48 & 59 & 87 & 0,9 & 131 & 118 & 190 & 205 & 1,08 \\
\hline \multicolumn{13}{|c|}{ DRG Solunum Sistemi Enfeksiyon Vaka Karma İndeksleri (Avustralya) } \\
\hline & \multicolumn{3}{|c|}{ E62A } & \multicolumn{3}{|c|}{ E62B } & \multicolumn{3}{|c|}{ E62C } & \multirow[b]{2}{*}{$\begin{array}{c}\text { Toplam } \\
\text { Vaka Sayısı }\end{array}$} & \multirow{2}{*}{$\begin{array}{c}\text { Toplam } \\
\text { Ağırlıklandırılmış } \\
\text { Vaka }\end{array}$} & \multirow[b]{2}{*}{ VKi } \\
\hline Hastaneler & $\begin{array}{l}\text { Bağıl } \\
\text { Değer }\end{array}$ & $\begin{array}{l}\text { Vaka } \\
\text { Sayısı }\end{array}$ & $\begin{array}{c}\text { Ağırlıkl. } \\
\text { Vaka }\end{array}$ & $\begin{array}{l}\text { Bağıl } \\
\text { Değer }\end{array}$ & $\begin{array}{l}\text { Vaka } \\
\text { Sayısı }\end{array}$ & $\begin{array}{c}\text { Ağırlıklandırılmış } \\
\text { Vaka }\end{array}$ & $\begin{array}{l}\text { Bağıl } \\
\text { Değer }\end{array}$ & $\begin{array}{l}\text { Vaka } \\
\text { Sayısı }\end{array}$ & $\begin{array}{c}\text { Ağırlıklandırılmış } \\
\text { Vaka }\end{array}$ & & & \\
\hline A Hastanesi & 2,56 & 346 & 886 & 1,88 & 1129 & 2123 & 1,06 & 1093 & 1159 & 2568 & 4167 & 1,62 \\
\hline B Hastanesi & 2,56 & 192 & 492 & 1,88 & 862 & 1621 & 1,06 & 855 & 906 & 1909 & 3018 & 1,58 \\
\hline C Hastanesi & 2,56 & 26 & 67 & 1,88 & 372 & 699 & 1,06 & 1210 & 1283 & 1608 & 2049 & 1,27 \\
\hline D Hastanesi & 2,56 & 0 & 0 & 1,88 & 59 & 111 & 1,06 & 131 & 139 & 190 & 250 & 1,31 \\
\hline \multicolumn{13}{|c|}{ DRG Solunum Sistemi Enfeksiyon Vaka Karma İndeksleri (Almanya) } \\
\hline & \multicolumn{3}{|c|}{ E62A } & \multicolumn{3}{|c|}{ E62B } & \multicolumn{3}{|c|}{ E62C } & \multirow[b]{2}{*}{$\begin{array}{c}\text { Toplam } \\
\text { Vaka Sayısı }\end{array}$} & \multirow{2}{*}{$\begin{array}{c}\text { Toplam } \\
\text { Ağırlıklandırılmış } \\
\text { Vaka }\end{array}$} & \multirow[b]{2}{*}{ VKI } \\
\hline Hastaneler & $\begin{array}{l}\text { Bağıl } \\
\text { Değer }\end{array}$ & $\begin{array}{l}\text { Vaka } \\
\text { Sayısı } \\
\end{array}$ & $\begin{array}{l}\text { Ağırlıkl. } \\
\text { Vaka } \\
\end{array}$ & $\begin{array}{l}\text { Bağıl } \\
\text { Değer }\end{array}$ & $\begin{array}{l}\text { Vaka } \\
\text { Sayısı } \\
\end{array}$ & $\begin{array}{c}\text { Ağırlıklandırılmış } \\
\text { Vaka }\end{array}$ & $\begin{array}{l}\text { Bağıl } \\
\text { Değer }\end{array}$ & $\begin{array}{l}\text { Vaka } \\
\text { Sayısı } \\
\end{array}$ & $\begin{array}{c}\text { Ağırlıklandırılmış } \\
\text { Vaka }\end{array}$ & & & \\
\hline A Hastanesi & 2,96 & 595 & 1761 & 1,86 & 1973 & 3670 & - & & & 2568 & 5431 & 2,11 \\
\hline B Hastanesi & 2,96 & 347 & 1027 & 1,86 & 1562 & 2905 & - & & & 1909 & 3932 & 2,06 \\
\hline C Hastanesi & 2,96 & 123 & 364 & 1,86 & 1485 & 2762 & - & & & 1608 & 3126 & 1,94 \\
\hline D Hastanesi & 2,96 & 0 & 0 & 1,86 & 190 & 353 & - & & & 190 & 353 & 1,86 \\
\hline
\end{tabular}

Tablo 9'da hastanelerin vaka karma indeksleri ülke bağıl değerlerine göre belirlenmiştir. Almanya'da solunum sistemi enfeksiyon vakaları Türkiye ve Avustralya'da olduğu gibi 3 ciddiyet düzeyine göre değil (E62A - B ve C) 2 ciddiyet (E62A ve E62B) düzeyine göre belirlenmiştir. Bu nedenle E62C vaka sayıları, hastanelerin E62A ve E62B vaka sıklık oranlarına göre bu vakalara dağıtılmıştır.

Aynı DRG algoritmasını (AR DRG) kullanan 3 ülkede ülkelerin kendine özgü olarak DRG algoritmalarını zamanla şekillendirmeleri nedeniyle farklılıklar oluşabildiği görülmüştür. Aynı şekilde Almanya için 3, diğer ülkeler için daha az ya da fazla ciddiyet düzeyleri ülkelerin yapılarına göre yaptığı analizler sonucu revize edilerek farklılık gösterebilecektir. 
Vaka Karma İndeksi hastanelerin diğer hastanelere göre ne derece daha komplike yani aslında maliyetli vaka baktıklarını ortaya koyan bir değerdir. Bu değer; özellikle hastanelere yapılacak geri ödemede, doğrudan bir çarpan olması nedeniyle maliyetli vaka yani yüksek bağıl değerli hasta bakan hastaneler için daha adil ve hakkaniyetli bir kaynak dağıtımının sağlanmasında önemli bir parametredir.

Vaka Karma İndeksi hesaplamalarında doğrudan bir çarpan oran vaka Bağıl Değerlerine bakıldığında her üç vaka içinde en düşük Bağıl Değerler ve dolayısıyla Vaka Karma İndeksleri Türkiye'nin çıkmıştır. Almanya E62A vakasında önemli bir farkla yüksek, Avustralya ise E62B vakasında önemsiz sayılabilecek bir farkla yüksek Bağıl Değerlere sahip çıkmıştır.

Hastane bazında değerlendirme yapıldığında ise Türkiye ve Avustralya Vaka Karma İndeksler sıralamaları aynı çıkmıştır. Ancak Avustralya Bağıl Değerlerinin yüksek olması nedeniyle VKI'leri de yüksektir. Almanya'da ise özelikle E62C vakasının olmaması nedeniyle Türkiye ve Avustralya verisinde VKİ açısından son sırada yer alan C Hastanesi, 3. Sıraya yüksselmiş, D Hastanesi ise son sıraya inmiştir. Hastane türleri açısından değerlendirme yapıldığında Almanya verisinden elde edilen verinin bu bakımdan uyumlu olduğunu göstermiştir. Yani Almanya verisi ile tüm Eğitim ve Araştırma Hastaneleri (A,B,C), D Hastanesinden daha fazla geri ödeme (vaka sayısına göre) alabilecektir. Türkiye ve Avustralya verisinden değerlendirme yapıldığında ise D Hastanesi, C Hastanesinden daha maliyetli (komplike) vaka bakması ortaya çıkmış olması nedeniyle, eğer aynı sayıda vaka baksalar idi daha fazla geri ödeme alabileceği söylenebilir. $\mathrm{Bu}$ durumun bir Eğitim ve Araştırma Hastanesi olan C Hastanesi'nin oransal olarak az miktarda E62A vakasına ve yine oransal olarak yüksek miktarda E62C ve sonrasında E62B vakasında sahip olmasından kaynaklandığını söylenebilir.

Bununla birlikte hastanelerin alacağı geri ödemede önemli bir etken VKİ ile hastanenin kar/zarar ilişkisini belirleyebilmek mümkün değildir. Önemli olan hastanelerin o vaka için ne kadar ortalama maliyete sahip olduklarının ve o vaka için tüm hastaneler ortalama maliyetinin ne olduğudur. Bu nedenle hastaneler için gerek Bağıl Değer belirlenmesi ve buna bağlı hesaplanan Vaka Karma İndekslerinin hesaplanmasında temel nokta, hangi tür hastanelerin aynı havuzda yer aldığı ya da farklı özellikteki hastanelerin aynı havuzda yer alıp almamasıdır. Hastanelerin hizmet sunum kaynakları birbirinden farklılık göstereceğinden bu farklılıkları en aza indirecek şekilde hastane türlerine göre Bağıl Değer setleri oluşturulması daha doğru bir yaklaşım olabilir. 


\section{SONUÇ ve ÖNERILER}

2011 yılına ait Solunun Sistemi Enfeksiyonu vakalarından elde edilen verilerle 3'ü Eğitim ve Araştırma Hastanesi, 1’i Özel Dal Devlet Hastanesi olmak üzere 4 Sağlık Bakanlığı hastanesinde yapılan çalışma sonuçlarını şöyle özetlenebilir:

- E62 vakaları erkeklerde kadınlara göre daha sık görülmektedir.

- E62 vakalarının yaş ortalaması 53 olup, ciddiyet düzeyi yükseldikçe yaş ortalaması da yükselmektedir.

- Yaş ve cinsiyet açısından hastaneler arasında genel olarak farklılık bulunmamakta, ancak özelikle A Hastanesi’nde E62C yaş ortalamasının çok daha düşük seyrettiği görülmüştür.

- Vakaların ciddiyet düzeyleri (bağıl değerleri) ile ortalama kalış süreleri arasında negatif yönde ilişki olduğu görülmüştür.

- Hastanelerin alacakları geri ödemeleri, DRG çeşitlilikleri ve bağıl değerleri belirlemektedir. Bağgl değerleri yüksek olan DRG'lere sahip hastanelerin daha yüksek geri ödemeler alacakları, bağıl değerleri daha düşük olan DRG'leri içeren hastanelerin ise daha düşük geri ödemeler alacakları ortaya çıkmıştır.

- Hastane Vaka Karma İndeksleri ile hastanelerin alacakları geri ödeme miktarları arasında pozitif yönlü ilişki olduğu görülmüştür. Vaka Karma İndeksleri ile hastane türleri arasında ilişki olduğu görülmüş, daha yüksek VKİye sahip hastaneler Eğitim ve Araştırma Hastaneleri çıkmıştır.

- Ülkeler açısından değerlendirildiğinde ise ülkelerin DRG algoritmalarının farklılık gösterebileceği ortaya çıkmış, her ülkenin kendi sağlık ve maliyet yapısını yansıtan Bağıl Değerlerin kendilerine özgü olmaları nedeniyle başka ülkeler için kullanılmasının doğru bir yaklaşım olmadığı görülmüştür.

Çalışma sonuçları değerlendirildiğinde özellikle daha komplike olan vakaların Eğitim ve Araştırma Hastanelerinde tedavi edilmesinden dolayı bu tür hastanelerde daha yüksek vaka maliyetleri görülmektedir. Eğitim ve Araştırma Hastanelerinin 3. Basamak sağlık kurumu olması nedeniyle eğitim ve araştırma fonksiyonu da bulunmakta, daha nitelikli ve profesyonel insan kaynakları görev yapmakta ve daha donanımlı tıbbi malzeme ve cihazlar kullanılmaktadır. Sağlık hizmeti geri ödemelerinde hastane türleri arasındaki farklılıkların göz önünde bulundurulmak suretiyle bağıl değerlerin belirlenmesi ile daha adaletli ve hakkaniyetli 
geri ödeme yapılmasına imkan sağlayacağı düşünülmektedir. Ayrıca daha geniş bir evren ile çalışmanın yapılması daha doğru sonuçlar ortaya koyacağı ve diğer DRG vakaları için de benzer çalışmaların yapılması bu konuda rol alan aktörler açısından yol gösterici bilgiler sağlayacağı değerlendirilmektedir.

Son olarak neredeyse tüm gelişmiş ülkelerde uygulamaya geçmiş olan DRG uygulamasının sağlık kurumlarına daha adil ve bilimsel temelli bir finansman sağlamanın dışında; hastanelerin kuruluş yeri, kapasite ve hizmet türlerinin belirlenmesi, insan kaynakları planlaması ve donanım ihtiyaçlarının belirlenmesi, Birinci basamak sağlık hizmetlerinin yönlendirilmesi gibi sağlığın her alanında yerel ve ulusal bazda önemli katkılar sağlayacağı düşünülmektedir.

\section{KAYNAKÇA}

Hacettepe Üniversitesi Sağlık Hizmetleri Finansman Yapısının Güçlendirilmesi ve Yeniden Yapılandırılması için Altyapı Geliştirme Projesi (2006) "Ulusal DRGs Geliştirilmesi Çalışmalarının Sonuçları", (D.B.3.2) Raporu, TCHEALTH Bilgi Teknolojileri Ltd.Şti.

http://www.health.gov.au, erişim: 10.03.2014

http://www.g-drg.de, erişim: 12.03.2014

http://www.saglik.gov.tr, erişim: 10.03.2014

http://www.saglikvakti.com,erişim: $12.03 .2014^{1} \mathrm{G}$

Sağlık Bakanlığı Teşhis İlişkili Gruplar Daire Başkanlığı, http:// www.tig.saglik.gov.tr, erişim: 16.12.2013

Şencan, İ., Demir, M. (2013); Sağglı Bakanlığı Teşhis İlişkili Gruplar İleri Klinik Kodlama Standartları Kitabı, Ankara

Tanı İlişkili Gruplar (TİG) e-Bülteni. (2009), "Maliyetlendirmeye İlişkin Sıkça Sorulan Sorular”, Sayı 8. Mart Nisan, s. 16

TİG Uygulama Rehberi. (2011), Sağlık Bakanlığı Tedavi Hizmetleri Genel Müdürlüğü Performans Yönetimi ve Kalite Geliştirme Daire Başkanlı̆̆ Yayınları, Ankara 